\title{
A checklist for endonasal transsphenoidal anterior skull base surgery
}

\author{
Edward R. Laws, MD, ${ }^{1}$ Judith M. Wong, MD, MPH, ${ }^{2}$ Timothy R. Smith, MD, PhD, MPH, ${ }^{1}$ \\ Kenneth de los Reyes, MD, ${ }^{3}$ Linda S. Aglio, MD, MS, ${ }^{4}$ Alison J. Thorne, RN, MS, ${ }^{1}$ \\ David J. Cote, BS, ${ }^{1}$ Felice Esposito, MD, PhD, ${ }^{5}$ Paolo Cappabianca, MD, ${ }^{6}$ and \\ Atul Gawande, MD, MPH ${ }^{7}$
}

Departments of ${ }^{1}$ Neurosurgery, ${ }^{4}$ Anesthesiology, Perioperative and Pain Medicine, and ${ }^{7}$ Surgery, Brigham and Women's Hospital, Boston, Massachusetts; ' 2 Department of Neurosurgery, University of Southern California, Los Angeles; ${ }^{3}$ Department of Neurosurgery, Loma Linda University, Loma Linda, California; ${ }^{5}$ Department of Neurosurgery, University of Messina, Italy; and ${ }^{6}$ Department of Neurosurgery, University of Naples Federico II, Naples, Italy

OBJECTIVE Approximately 250 million surgical procedures are performed annually worldwide, and data suggest that major complications occur in 3\%-17\% of them. Many of these complications can be classified as avoidable, and previous studies have demonstrated that preoperative checklists improve operating room teamwork and decrease complication rates. Although the authors' institution has instituted a general preoperative "time-out" designed to streamline communication, flatten vertical authority gradients, and decrease procedural errors, there is no specific checklist for transnasal transsphenoidal anterior skull base surgery, with or without endoscopy. Such minimally invasive cranial surgery uses a completely different conceptual approach, set-up, instrumentation, and operative procedure. Therefore, it can be associated with different types of complications as compared with open cranial surgery. The authors hypothesized that a detailed, procedure-specific, preoperative checklist would be useful to reduce errors, improve outcomes, decrease delays, and maximize both teambuilding and operational efficiency. Thus, the object of this study was to develop such a checklist for endonasal transsphenoidal anterior skull base surgery.

METHODS An expert panel was convened that consisted of all members of the typical surgical team for transsphenoidal endoscopic cases: neurosurgeons, anesthesiologists, circulating nurses, scrub technicians, surgical operations managers, and technical assistants. Beginning with a general checklist, procedure-specific items were added and categorized into 4 pauses: Anesthesia Pause, Surgical Pause, Equipment Pause, and Closure Pause.

RESULTS The final endonasal transsphenoidal anterior skull base surgery checklist is composed of the following 4 pauses. The Anesthesia Pause consists of patient identification, diagnosis, pertinent laboratory studies, medications, surgical preparation, patient positioning, intravenous/arterial access, fluid management, monitoring, and other special considerations (e.g., Valsalva, jugular compression, lumbar drain, and so on). The Surgical Pause is composed of personnel introductions, planned procedural elements, estimation of duration of surgery, anticipated blood loss and fluid management, imaging, specimen collection, and questions of a surgical nature. The Equipment Pause assures proper function and availability of the microscope, endoscope, cameras and recorders, guidance systems, special instruments, ultrasonic microdoppler, microdebrider, drills, and other adjunctive supplies (e.g., Avitene, cotton balls, nasal packs, and so on). The Closure Pause is dedicated to issues of immediate postoperative patient disposition, orders, and management.

CONCLUSIONS Surgical complications are a considerable cause of death and disability worldwide. Checklists have been shown to be an effective tool for reducing preventable errors surrounding surgery and decreasing associated complications. Although general checklists are already in place in most institutions, a specific checklist for endonasal transsphenoidal anterior skull base surgery was developed to help safeguard patients, improve outcomes, and enhance teambuilding.

http://thejns.org/doi/abs/10.3171/2015.4.JNS142184

KEY WORDS endonasal; transsphenoidal; checklist; skull base; endoscopic; microscopic; pituitary surgery

ABBREVIATION SSC = Surgical Safety Checklist.

SUBMITTED September 30, 2014. ACCEPTED April 7, 2015.

INCLUDE WHEN CITING Published online October 30, 2015; DOI: 10.3171/2015.4.JNS142184. 
$\mathrm{S}$ URGICAL complications have long been a major and well-documented source of morbidity and mortality. In the earliest days of neurosurgery, mortality rates reached as high as $80 \%$ for some operations, and complications were exceedingly common. ${ }^{24}$ Even in the best of hands, the transsphenoidal approach to the skull base had mortality rates as high as $5.6 \%$ in the early $1900 \mathrm{~s} .{ }^{20}$ Subsequently, there has been a significant decline in complication and mortality rates as a result of the vast expansion of medical knowledge, improved technologies, and higher standards of care. ${ }^{20}$ Nevertheless, approximately 250 million surgical procedures are performed annually as a crucial part of comprehensive health care worldwide, with major complications arising in 3\%-17\% of patients (7.542.5 million). ${ }^{5,16}$ When considering all complications, the rate increases to $27 \%-42 \%$ of patients, with many coming from high-risk specialties such as neurosurgery, thoracic/ cardiovascular surgery, and orthopedic surgery. ${ }^{17}$

In neurosurgical procedures, these complications can vary widely. ${ }^{34-38}$ In endonasal transsphenoidal neurosurgical procedures, complications include CSF leak, vision loss, hemorrhage, epistaxis, postoperative infection, and, rarely, death. ${ }^{21}$ Although these transsphenoidal operations are considered relatively safe in comparison with open cranial procedures, overall complication rates nevertheless are reported as around $20 \%$ for primary endoscopic transnasal operations, with repeat operations having slightly higher rates. ${ }^{2,19}$ Limiting the number and severity of surgical complications in endonasal transsphenoidal procedures therefore continues to be a major goal in improving patient safety and maximizing patient outcomes.

One relatively recent strategy for decreasing the surgical complication rate has been the introduction of the surgical checklist. $6,9,12,13,14,17,23,32$ These checklists, inspired by the aviation industry, have been widely adopted in the US and internationally as a way to avoid surgical complications. ${ }^{915,28,29}$ Similar to those used in aviation, the checklists serve 3 main functions: first, to ensure that basic safety checks have been performed; second, to ensure that all necessary equipment is present and functioning properly; and third, to promote teambuilding and effective communication. Although these checklists can never substitute for proper, thorough training or surgical experience, studies have shown that the use of checklists in surgical procedures significantly improves response to intraoperative and anesthetic crises, flattens vertical authority gradients, and decreases complication rates. . $^{1,3,9,11,15,23,24,27,37}$ The implementation of checklists in both inpatient and surgical settings is also cost-effective, has improved the medical-legal environment, and has increased health care efficiency. ${ }^{8,26}$ Patients also view checklists favorably. ${ }^{25}$

As a discipline, neurosurgery is exploring more precise standardization methods and more comprehensive approaches for tracking patient outcomes. Recent evidence indicates the role for additional, procedure-specific checklists, which could standardize treatment and reduce neurosurgical risk. ${ }^{34-38,40}$ The purpose of this study was to develop a checklist that is highly specific to endonasal transsphenoidal anterior skull base procedures and can be modified in accordance with a variety of surgical practice settings.

\section{Methods}

A committee was formed that included all team members of a typical endonasal endoscopic transsphenoidal anterior skull base operation. These included neurosurgeons from the US and Europe, anesthesiologists, circulating nurses, scrub technicians, surgical operations managers, and technical assistants. Many members of the committee, including a neurosurgeon, an anesthesiologist, and a circulating nurse, were part of an operative team that has performed more than 700 of these operations over an 8-year period. The senior author (E.R.L.), who served as chair of the committee, has personally performed more than 5700 transsphenoidal operations.

Once formed, the committee was directed to determine the contents of a concise, procedure-specific checklist for transsphenoidal operations, with the intention of decreasing the surgical complication rate and improving patient outcomes. The WHO's Surgical Safety Checklist (WHO SSC) was used as a template. Adapting the successful design strategy of checklists in aviation and manufacturing procedures, the development of the checklist was carried out in several stages: content and format, timing, trial and feedback, formal testing and evaluation, and local modification. ${ }^{33}$

After early discussions, a prototype of the checklist was developed and evaluated independently by each member of the committee for verification and modification. The resultant second-stage checklist was then used in a surgical setting at our institution to verify the checklist's functionality and to improve its contents by trial and feedback.

\section{Results}

The final comprehensive transsphenoidal operation checklist is presented in Fig. 1. The checklist includes all aspects of the WHO SSC, with additional items categorized into 4 pauses. These correlate with the natural pauses in a typical transsphenoidal operation. It is meant to be a structured guide that can readily be modified and shortened when applied to different practice settings. As stated, it reflects the nuances of practice in our multidisciplinary setting.

\section{Anesthesia Pause}

The first pause, the Anesthesia Pause, is read aloud prior to the induction of anesthesia. This section of the checklist includes the preanesthesia elements of the SSC (e.g., patient identification, allergies), in addition to concerns of particular importance in transsphenoidal operations. Comorbidities associated with acromegaly and Cushing's disease are common in transsphenoidal operations for pituitary conditions. They have very particular effects on the ease of intubating the patient, accessing the sphenoid, and ultimately performing a successful procedure. This checklist provides for identification of these concerns prior to the beginning of the operation. Laboratory values and medications related to these comorbidities are also particularly important to discuss when patients have a dysfunctional pituitary axis; thus, they were added to this checklist.

Several other items were added to this pause to ensure 


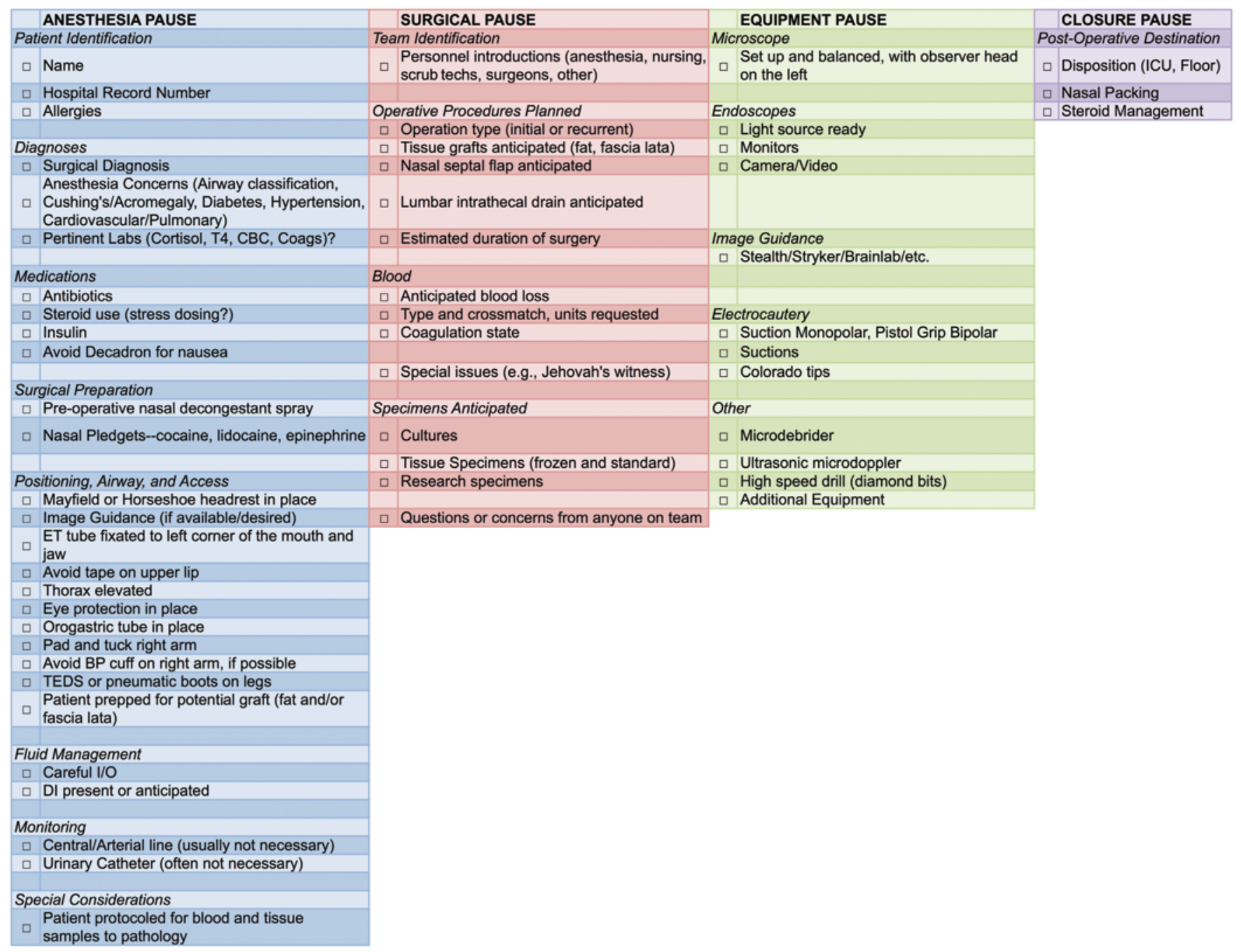

FIG. 1. A checklist for transnasal transsphenoidal anterior skull base surgery is shown. $\mathrm{BP}=$ blood pressure; $\mathrm{DI}=$ diabetes insipidus; ET = endotracheal; I/O = intake/output; Pertinent Labs = Pertinent Laboratory Values; TEDS = thromboembolic deterrent stockings. Figure is available in color online only.

appropriate patient preparation before commencement of the operation. The administration of preoperative nasal decongestants is helpful to ease access and control bleeding; fiducials for image guidance allow for a more precise approach to the sphenoid; preparation of potential tissue graft sites allows for more efficient access and excision later in the procedure; and avoidance of tape or other mechanical barriers on the upper lip, elevation of the thorax, and proper placement of the endotracheal and orogastric tubes all permit easier access to the nostrils by the surgical team. Similarly, proper placement of the patient's right arm, patient's body, and bed orientation allow for a more ergonomic operating posture for the chief surgeon.

Manipulation of the posterior pituitary gland increases the incidence of intra- and postoperative syndrome of inappropriate antidiuretic hormone secretion and diabetes insipidus during transsphenoidal operations. Careful monitoring of fluid intake and output before, during, and after the operation is crucial to proper diagnosis of these electrolyte disturbances. Arterial lines and urinary catheters are generally unnecessary for routine transsphenoi- dal operations, but should be considered prior to induction of anesthesia if they are required. The final section of the Anesthesia Pause ensures proper protocol for collection of tissue and blood samples for pathology and/or research.

\section{Surgical Pause}

The Surgical Pause should be read aloud prior to surgical commencement. As in the WHO SSC, this pause prioritizes identification of the type, location, and estimated duration of the operation. Preparation for possible blood transfusion remains as important in this checklist as in the WHO SSC, with specific provisions to ensure that blood is available, appropriate to the patient, and properly labeled. Specific maneuvers common in transsphenoidal operations, such as tissue grafts, nasal septal flaps, and lumbar intrathecal drains, should be discussed aloud prior to beginning the operation, as well as the potential need for research sample collection.

\section{Equipment Pause}

Transsphenoidal operations require a novel set of in- 
struments compared with typical intracranial operations. Some of these instruments may be unfamiliar to surgical teams that perform few endoscopic procedures. Transsphenoidal operations occasionally require the support of both endoscope and microscope. As such, both should be properly prepared and available, and both are included in the checklist. The preparation of the endoscope is of particular importance in transsphenoidal operations; proper functioning of the monitors, cameras, video recording software, and light source, as well as preparation with Clearvision (Karl Storz), helps to ensure adequate visualization of the sella and the surgical target. Similarly, preparation of the image guidance system in use (e.g., Stryker, Brainlab) allows for a safer and more precise approach.

The final section of the Equipment Pause covers several crucial instruments in transsphenoidal operations. Electrocautery, suction, and microdebrider allow access to the sphenoid through the nasal cavity; a microdoppler instrument enables localization and subsequent avoidance of the cavernous carotid arteries; and a drill with 3-4-mm diamond bits allows for more aggressive bone preparation, if necessary.

\section{Closure Pause}

The final pause in the checklist, the Closure Pause, should be read aloud before the patient leaves the operating room. It is mostly concerned with finalizing the procedure and determining the destination of the patient postoperatively (e.g., to a neurosurgical floor, the neurosurgical intensive care unit, and so on), pertinent disease-specific postoperative orders, and any other perioperative management issues.

\section{Discussion}

In general, the aviation industry has used preflight checklists to enhance safety and teambuilding, for reliability and reproducibility of results, as a precaution against untoward events, and for clarification of roles and responsibilities. ${ }^{3,33}$ Although checklists are not a substitute for experience and technical expertise, they are steadily growing in popularity and usefulness in surgical practices worldwide. ${ }^{10,16,30}$ These general checklists serve an important function in averting catastrophic surgical complications, such as wrong-site, wrong-procedure, or wrong-patient operations..$^{22,39}$ They similarly help prevent adverse surgical outcomes by ensuring basic steps for patient safety, such as identifying a patient's allergies and encouraging sterility in the operating room..$^{4,14,16,34}$

Systematic reviews of the introduction and implementation of these checklists have been overwhelmingly positive, with general decreases in surgical complication rates and reports of improved operating room teamwork and communication. ${ }^{26}$ In a randomized, controlled trial of safety checklist use in 5 disciplines (cardiothoracic, neurological, orthopedic, general, and urological surgery), Haugen et al. reported a decrease in complication rates from $19.9 \%$ to $11.5 \%$ ( $\mathrm{p}<0.001$ ) between 2212 control procedures and 2263 procedures under the WHO SSC..$^{15}$ Even after adjusting for confounding factors, the effect of the WHO SSC on surgical complications was significant, with an OR of 1.95. The mean hospital stay also decreased by almost a day.

In a separate study, de Vries et al. compared 3760 patients before implementation of a surgical safety checklist with 3820 patients observed after implementation..$^{10}$ They reported a decrease in number of complications per 100 patients from 27.3 to 16.7 , an absolute risk reduction of 10.6 , and a decrease in in-hospital mortality from $1.5 \%$ to $0.8 \% .^{10}$

Checklists have also been shown to improve patient safety specifically in neurosurgery. Lepänluoma et al. reported a reduction in unplanned readmissions from $25 \%$ to $10 \%(\mathrm{p}=0.02)$ after implementation of a neurosurgical safety checklist, while wound complications decreased from $19 \%$ to $8 \%(p=0.04){ }^{23}$ Operating room personnel were also surveyed regarding the implementation of the surgical checklist; an improvement in communication was found among team members as well as improved procedural documentation. Although their adoption into practice has been somewhat slow, it is clear from the data that surgical safety checklists have had a positive impact on patient safety. ${ }^{22,31}$

Procedure-specific checklists similar to those designed here help standardize specific operations, act as a qualitycontrol mechanism, improve efficiency, and can help to ensure the best possible outcomes for patients. They are more detailed in nature than general safety checklists and build upon the role that these checklists have played by ensuring not only safety but also promoting the highest standard of care. One extension beyond the simple safety checklist is the concept of phase-change checklists..$^{18}$ Neurosurgical cases have critical phases, and taking a moment to stop and prepare for the next phase is helpful. The transsphenoidal checklist presented here incorporates this temporal aspect and has been designed with 4 pauses, or stages.

Although the checklist seeks to be procedure specific, it cannot be all inclusive. At some point, a line must be drawn between what is crucial to patient safety during a transsphenoidal skull base operation and what is simply a straightforward part of all neurosurgical operations. The instrument developed here is a middle ground between detailed surgical instructions and a general safety checklist. It ensures that the most basic and critical elements of any transsphenoidal operation are accounted for, while remaining concise enough to be used during the flow of an operation.

Nevertheless, the checklist developed here may appear unwieldy to some. Indeed, many experts recommend limiting the size of checklists to fewer than 10 items per pause point to avoid so-called "checklist fatigue." 13,33 Procedurespecific checklists necessarily deviate from this recommendation, because they are designed specifically to account for many different aspects of a particular operation that are at risk for being forgotten. The checklist developed here could serve as a crucial verification of preparedness, promoting consistent and uniform performance. Although the checklist designed here cannot replace the benefits of thorough training and an experienced surgeon, it can help ensure that catastrophic disaster, undue delay, and poor communication are avoided to the greatest ex- 
tent possible. Neurosurgical procedures are not amenable to "cookbook" procedural lists or "autopilot" mentalities. There will be significant variation among neurosurgical centers and treatment teams, and this checklist reflects one center's experience only, providing a framework for modification by other centers.

Neurosurgery is a high-risk surgical discipline. Nevertheless, many of the complications that result from these operations should be considered preventable. In a review of adverse outcomes in neurosurgical procedures, researchers found that many complications resulted from difficulties in communication or variations in equipment. ${ }^{34} \mathrm{Al}$ though some risks may be considered avoidable, problems with equipment and communication can largely be countered by effective implementation and regular use of a surgical checklist. ${ }^{4,7,10}$ By implementing procedure-specific checklists such as the one developed here, the benefits of a safety checklist can be combined with the expertise of a skilled neurosurgical team to provide multidisciplinary patient care of the highest quality and effectiveness.

Studies are underway to determine the effects of this checklist on patient outcomes during transsphenoidal operations and to determine whether implementation of such a checklist has any effect on the complication rate. Should the data indicate successful improvement in patient safety, further investigations are planned to develop appropriate checklists for other neurosurgical operations.

\section{Conclusions}

Surgical complications are a considerable cause of death and disability worldwide. Checklists have been shown to be an effective tool for reducing preventable errors surrounding surgery and decreasing associated complications. Although general checklists are already in place in most institutions, a specific checklist for endonasal transsphenoidal anterior skull base surgery can safeguard patients by ensuring that proper safety measures have been followed, team members are fully briefed for the procedure, and patients are assured optimal outcomes.

\section{Acknowledgment}

We thank Angela M. Bader, MD, MPH, for her assistance in preparing the checklist.

\section{References}

1. Arriaga AF, Bader AM, Wong JM, Lipsitz SR, Berry WR, Ziewacz JE, et al: Simulation-based trial of surgical-crisis checklists. N Engl J Med 368:246-253, 2013

2. Barker FG II, Klibanski A, Swearingen B: Transsphenoidal surgery for pituitary tumors in the United States, 1996-2000: mortality, morbidity, and the effects of hospital and surgeon volume. J Clin Endocrinol Metab 88:4709-4719, 2003

3. Bienefeld N, Grote G: Shared leadership in multiteam systems: how cockpit and cabin crews lead each other to safety. Hum Factors 56:270-286, 2014

4. Birkmeyer JD: Strategies for improving surgical qualitychecklists and beyond. N Engl J Med 363:1963-1965, 2010

5. Birkmeyer JD, Siewers AE, Finlayson EV, Stukel TA, Lucas FL, Batista I, et al: Hospital volume and surgical mortality in the United States. N Engl J Med 346:1128-1137, 2002

6. Boaz M, Bermant A, Ezri T, Lakstein D, Berlovitz Y, Laniado I, et al: Effect of Surgical Safety checklist implementation on the occurrence of postoperative complications in orthopedic patients. Isr Med Assoc J 16:20-25, 2014

7. Conley DM, Singer SJ, Edmondson L, Berry WR, Gawande AA: Effective surgical safety checklist implementation. J Am Coll Surg 212:873-879, 2011

8. Curry WT, McDermott MW, Carter BS, Barker FG II: Craniotomy for meningioma in the United States between 1988 and 2000: decreasing rate of mortality and the effect of provider caseload. J Neurosurg 102:977-986, 2005

9. de Vries EN, Eikens-Jansen MP, Hamersma AM, Smorenburg SM, Gouma DJ, Boermeester MA: Prevention of surgical malpractice claims by use of a surgical safety checklist. Ann Surg 253:624-628, 2011

10. de Vries EN, Prins HA, Crolla RM, den Outer AJ, van Andel $\mathrm{G}$, van Helden SH, et al: Effect of a comprehensive surgical safety system on patient outcomes. N Engl J Med 363:19281937, 2010

11. Dell'Atti L: [Introduction of a checklist to reduce adverse events in urologic surgery: our experience.] Urologia 80:239-243, 2013 (Ital)

12. Diamond S, El Tal AK, Mehregan D: A dermatology surgical safety checklist: an objective resident performance tool. Int J Dermatol 52:1231-1234, 2013 (Erratum in Int J Dermatol 52:1626, 2013)

13. Gawande AA, Boorman D: Checklist for checklists. Project Check. (http://www.projectcheck.org/checklist-forchecklists.html) [Accessed August 14, 2015]

14. Gillespie BM, Chaboyer W, Thalib L, John M, Fairweather $\mathrm{N}$, Slater K: Effect of using a safety checklist on patient complications after surgery: a systematic review and metaanalysis. Anesthesiology 120:1380-1389, 2014

15. Haugen AS, Søfteland E, Almeland SK, Sevdalis N, Vonen B, Eide GE, et al: Reply to "Letter to Editor Concerning the Article-Effect of the World Health Organization Checklist on Patient Outcomes: A Stepped Wedge Cluster Randomized Controlled Trial." Ann Surg [epub ahead of print], 2014

16. Haynes AB, Weiser TG, Berry WR, Lipsitz SR, Breizat AH, Dellinger EP, et al: A surgical safety checklist to reduce morbidity and mortality in a global population. N Engl J Med 360:491-499, 2009

17. Healey MA, Shackford SR, Osler TM, Rogers FB, Burns E: Complications in surgical patients. Arch Surg 137:611-618, 2002

18. Kerber CW: Changing our culture: adopting the military aviation safety system. J Neurointerv Surg 6:332-341, 2014

19. Laws ER: The endoscopic endonasal approach for recurrent pituitary lesions. World Neurosurg 80:272-273, 2013

20. Laws ER: History of pituitary surgery, in Schwartz T, Anand VK (eds): Endoscopic Pituitary Surgery. New York: Thieme, 2012, pp 1-8

21. Laws ER, Raber MR, Iuliano SL: Complications of endoscopic pituitary surgery and strategies for their avoidance, in Misra BK, Laws ER, Kaye AH (eds): Current Progress in Neurosurgery. Mumbai: Tree Life Media, 2014, pp 46-54

22. Lee AJ, Raniga S, Hooper G, Perry A, Bisset R, Darley D, et al: The Time Out Procedure: have we changed our practice? N Z Med J 125:26-35, 2012

23. Lepänluoma M, Takala R, Kotkansalo A, Rahi M, Ikonen TS: Surgical safety checklist is associated with improved operating room safety culture, reduced wound complications, and unplanned readmissions in a pilot study in neurosurgery. Scand J Surg 103:66-72, 2014

24. Maartens NF, Kaye AH: Role of transcranial approaches in the treatment of sellar and suprasellar lesions. Front Horm Res 34:1-28, 2006

25. Papaconstantinou HT, Jo C, Reznik SI, Smythe WR, WehbeJanek H: Implementation of a surgical safety checklist: impact on surgical team perspectives. Ochsner J 13:299-309, 2013 
26. Russ S, Rout S, Sevdalis N, Moorthy K, Darzi A, Vincent C: Do safety checklists improve teamwork and communication in the operating room? A systematic review. Ann Surg 258:856-871, 2013

27. Russ SJ, Rout S, Caris J, Moorthy K, Mayer E, Darzi A, et al: The WHO surgical safety checklist: survey of patients' views. BMJ Qual Saf 23:939-946, 2014

28. Semel ME, Resch S, Haynes AB, Funk LM, Bader A, Berry WR, et al: Adopting a surgical safety checklist could save money and improve the quality of care in U.S. hospitals. Health Aff (Millwood) 29:1593-1599, 2010

29. Takala RS, Pauniaho SL, Kotkansalo A, Helmiö P, Blomgren $\mathrm{K}$, Helminen M, et al: A pilot study of the implementation of WHO surgical checklist in Finland: improvements in activities and communication. Acta Anaesthesiol Scand 55:12061214,2011

30. Urbach DR, Govindarajan A, Saskin R, Wilton AS, Baxter NN: Introduction of surgical safety checklists in Ontario, Canada. N Engl J Med 370:1029-1038, 2014

31. Wang M, Serak J: "Time out" for surgical safety checklists? Neurosurgery 75:N14-N15, 2014

32. Weiser TG, Berry WR: Review article: perioperative checklist methodologies. Can J Anaesth 60:136-142, 2013

33. Weiser TG, Haynes AB, Lashoher A, Dziekan G, Boorman DJ, Berry WR, et al: Perspectives in quality: designing the WHO Surgical Safety Checklist. Int J Qual Health Care 22:365-370, 2010

34. Wong JM, Bader AM, Laws ER, Popp AJ, Gawande AA: Patterns in neurosurgical adverse events and proposed strategies for reduction. Neurosurg Focus 33(5):E1, 2012

35. Wong JM, Panchmatia JR, Ziewacz JE, Bader AM, Dunn IF, Laws ER, et al: Patterns in neurosurgical adverse events: intracranial neoplasm surgery. Neurosurg Focus 33(5):E16, 2012

36. Wong JM, Ziewacz JE, Ho AL, Panchmatia JR, Bader AM, Garton HJ, et al: Patterns in neurosurgical adverse events: cerebrospinal fluid shunt surgery. Neurosurg Focus 33(5):E13, 2012
37. Wong JM, Ziewacz JE, Ho AL, Panchmatia JR, Kim AH, Bader AM, et al: Patterns in neurosurgical adverse events: open cerebrovascular neurosurgery. Neurosurg Focus 33(5):E15, 2012

38. Wong JM, Ziewacz JE, Panchmatia JR, Bader AM, Pandey AS, Thompson BG, et al: Patterns in neurosurgical adverse events: endovascular neurosurgery. Neurosurg Focus 33(5):E14, 2012

39. Ziewacz JE, Arriaga AF, Bader AM, Berry WR, Edmondson L, Wong JM, et al: Crisis checklists for the operating room: development and pilot testing. J Am Coll Surg 213:212-217. e10, 2011 (Erratum in J Am Coll Surg 215:310, 2012)

40. Zuckerman SL, Green CS, Carr KR, Dewan MC, Morone PJ, Mocco J: Neurosurgical checklists: a review. Neurosurg Focus 33(5):E2, 2012

\section{Disclosure}

Dr. Cappabianca is a consultant for Baxter and receives support from Karl Storz.

\section{Author Contributions}

Conception and design: all authors. Drafting the article: Smith, Laws, Cote. Critically revising the article: Smith, Laws, Wong, de los Reyes, Cote, Gawande. Reviewed submitted version of manuscript: all authors. Approved the final version of the manuscript on behalf of all authors: Smith. Administrative/technical/material support: Cote. Study supervision: Smith, Laws, Gawande.

\section{Correspondence}

Timothy R. Smith, Department of Neurosurgery, Brigham and Women's Hospital, 15 Francis St., PBB3, Boston, MA 02115. email: trsmith@partners.org. 